\title{
Uma avaliação da difusão de práticas de gestão da produção entre pequenas empresas em sistemas locais de produção
}

\author{
Renato Garcia ${ }^{a *}$, Paula Madeira ${ }^{\mathrm{b}}$ \\ a*renato.garcia@poli.usp.br, USP, Brasil \\ bpaulaxmadeira@gmail.com, USP, Brasil
}

\begin{abstract}
Resumo
Há uma preocupação crescente na literatura acerca dos principais determinantes da competitividade das empresas de pequeno e médio porte. Uma importante contribuição nesse sentido tem sido a consideração de que os sistemas locais de produção (comumente chamados no Brasil de APL) são capazes de propiciar benefícios que reforçam o aprimoramento produtivo dessas empresas. Com base nessa premissa principal, este trabalho tem o objetivo de investigar os efeitos da aglomeração no aprimoramento produtivo das pequenas empresas, através da análise do processo de difusão de práticas e ferramentas de gestão da produção em sistemas locais. Para tanto, o estudo contempla os resultados de um extenso levantamento de dados realizado em 42 empresas de pequeno porte, localizadas na aglomeração de produtores de calçados da cidade de Franca, no Estado de São Paulo. 0 estudo investigou a existência de processos de aprimoramento produtivo nas pequenas empresas locais e as principais fontes de informação para a difusão dessas práticas. Os resultados indicaram que a aglomeração das empresas no sistema local é capaz de contribuir para que elas adotem novas práticas de gestão da produção, seja por meio de mecanismos deliberados de difusão de novos conhecimentos entre os agentes, seja por meio da circulação espontânea de informações, típicas dessas estruturas produtivas localizadas. Além disso, foi possível verificar que o nível de apropriação desses benefícios dependeu dos conhecimentos já existentes na empresa, ou seja, de sua capacidade de absorção.
\end{abstract}

Palavras-chave

Pequenas e médias empresas. Gestão da produção. Sistemas Locais de Produção. Sistemas locais de produção. Clusters de empresas. Aprimoramento produtivo.

\section{Introdução}

Nos últimos anos, muitos estudos têm se dedicado às questões relacionadas aos determinantes da competitividade de pequenas e médias empresas e sua inserção na estrutura produtiva. Essa importância é reforçada quando do debate nos países em desenvolvimento, principalmente devido ao reconhecimento do papel das pequenas empresas como elementos-chave do desenvolvimento econômico e social de um país ou região, devido principalmente ao seu potencial para a geração de renda e empregos (SOUZA, 1995; LA ROVERE, 2001; ORGANIZATION..., 1997).

Entretanto, a despeito desse importante papel, as pequenas e médias empresas enfrentam problemas de diversas ordens, sobretudo relativos à sua própria condição de escala reduzida, carência de recursos e dificuldade de acesso a crédito; e também os problemas relativos à sua organização e estrutura interna que afetam seu desempenho, sendo notória a fragilidade em termos de capacitação gerencial. Como consequência, elas geralmente desconhecem novas tecnologias e práticas de gestão ou as ferramentas necessárias que permitem sua implementação de maneira eficaz (ORGANIZATION..., 1997). Além disso, as tecnologias de melhoramento produtivo são normalmente acompanhadas por mudanças no sistema de produção e na organização do trabalho, exigindo novas habilidades técnicas da mão de obra. 
Mesmo depois que a empresa conhece os benefícios associados à implantação de uma dada tecnologia, ainda existem incertezas em relação ao método mais adequado de adoção para que tal tecnologia seja integrada no ambiente operacional específico da empresa.

Isso demonstra que a implementação de novas tecnologias pelas empresas depende de processos de aprendizagem, que vão determinar a capacidade de absorção e aplicação dos novos conhecimentos e informações adquiridos (COHEN; LEVINTHAL, 1990). Como consequência, muitos estudos apontaram que as estruturas internas de gestão da produção representavam relevantes obstáculos para a adoção de novas tecnologias, decorrentes das deficiências organizacionais existentes nas suas estruturas de gestão. Muitos desses obstáculos ocorriam no nível da firma, uma vez que estão relacionados à sua capacidade de absorção (ORGANIZATION..., 1997).

Uma importante contribuição nesse sentido é que a aglomeração das empresas pode contribuir para o melhoramento produtivo e tecnológico dos produtores, devido às vantagens advindas da formação de sistemas locais de produção - mais comumente chamados no Brasil de APL (arranjos produtivos locais). Os sistemas locais propiciam um ambiente no qual é gerado um conjunto de benefícios que permitem às empresas melhores resultados do que se estivessem atuando isoladamente (MARSHALL, 1920; PORTER, 2000).

Seguindo essas premissas, este trabalho tem o objetivo de avaliar a contribuição da aglomeração industrial para o aprimoramento produtivo das pequenas e médias empresas, a partir de um foco nos processos de aquisição de novas capacitações que ocorrem no âmbito interno das empresas. Para isso, foram visitadas 42 empresas de micro e pequeno porte, situadas no sistema local da cidade de Franca, no Estado de São Paulo, com o objetivo de identificar a difusão de práticas de gestão da produção - o que, por sua vez, foi utilizado como um importante indicador da ocorrência de transbordamentos de conhecimento no âmbito do sistema local.

Este esforço está pautado em duas justificativas principais. Primeiro, porque, apesar das vantagens da aglomeração de produtores serem largamente citadas na literatura, existem poucos trabalhos que indicam mais especificamente quais desses mecanismos podem contribuir para melhorar o desempenho competitivo das empresas aglomeradas, especialmente no que se refere ao seu aprimoramento produtivo. Em segundo lugar, mas não menos importante, porque uma das características marcantes das pequenas empresas são suas deficiências em termos de gestão e de atualização técnica e tecnológica, principalmente nos setores mais intensivos em mão de obra. Entretanto, existe pouca evidência empírica sobre o potencial dos mecanismos de difusão local em propiciar a modernização e o processo de aprimoramento produtivo nesse universo de empresas no Brasil. E, por esse motivo, em muitos aspectos, esta temática ainda está por ser estudada.

\section{A abordagem e a dinâmica dos Sistemas Locais de Produção}

Diante das várias abordagens e conceitos acerca do fenômeno da aglomeração industrial, que são tomados de acordo com os objetivos dos diversos estudos na área, este trabalho utiliza o conceito de sistema local de produção, como apontado em Suzigan (2006). Além da caracterização do espaço econômico e da presença de agentes políticos e sociais que possuem vínculos produtivos e institucionais entre si, o conceito proposto também considera outros elementos.

Configura-se um sistema complexo em que operam diversos subsistemas de produção, logística e distribuição, comercialização, desenvolvimento tecnológico (P\&D, laboratórios de pesquisa, centros de prestação de serviços tecnológicos) e onde os fatores econômicos, sociais e institucionais estão fortemente entrelaçados (SUZIGAN, 2006, p. 14).

A definição proposta oferece uma concepção mais abrangente do fenômeno da aglomeração industrial, uma vez que, além da dimensão física e econômica (a existência de empresas produtoras de bens e serviços finais, fornecedoras de equipamentos e outros insumos, instituições correlatas e de apoio, entre outros), também engloba as operações de produção, destacando-se as interações entre os diversos elementos que compõem o sistema produtivo como um todo.

As vantagens observadas em sistemas locais de produção foram pioneiramente apontadas por Marshall (1920), a partir de experiências e estudos realizados nos distritos industriais ingleses no século XIX. Marshall apontou três forças principais que explicam a formação de aglomerações: primeiro, a existência concentrada de mão de obra qualificada com habilidades específicas ao setor; segundo, a presença de fornecedores especializados que garantem baixos custos e fácil acesso a produtos e serviços; e, em terceiro lugar, a ocorrência de transbordamentos de conhecimentos, chamados de spillovers, decorrentes da rápida difusão de conhecimentos decorrente da proximidade entre os agentes (SCHMITZ, 1997).

De acordo com Marshall (1920), a combinação entre esses fatores, aliada ao processo de especialização produtiva e à proximidade entre firmas, propicia o surgimento de externalidades positivas. As 
externalidades positivas representam ganhos de eficiência relacionados à forma de organização das empresas que não se encontram dentro delas, mas sim no ambiente externo que compõe a aglomeração de produtores. Nessa visão, as firmas se beneficiam da proximidade com outras empresas do mesmo ramo e também de setores e atividades correlatas. Além disso, o sistema local também abriga instituições de apoio, como instituições de pesquisa e de prestação de serviços e associações de classe que podem contribuir para o desenvolvimento de mão de obra qualificada e para a difusão de novas informações e conhecimentos.

Nos sistemas locais de produção, a forte especialização dos agentes econômicos permite que ocorra uma densa divisão do trabalho entre as firmas que, por sua vez, possibilita a interação frequente entre os atores locais a partir de relações comerciais e produtivas. Esses processos acarretam o aumento da produtividade das empresas e do sistema como um todo, além de ganhos obtidos na esfera organizacional. Com isso, as economias externas são geradas e intensificadas.

Outra importante contribuição dos estudos de Marshall foi a apresentação do conceito de transbordamentos de conhecimento (spillover). A interação entre produtores de bens finais com seus fornecedores, a mobilidade dos trabalhadores entre diferentes empresas e o monitoramento das empresas concorrentes contribuem para que os conhecimentos técnico-produtivos e informações sobre o mercado estejam disponíveis no sistema local de produção. Marshall representa esse fenômeno através da metáfora de que os conhecimentos específicos do setor "pairam no ar" e os segredos não podem ser guardados por muito tempo (MARSHALL, 1920). A atmosfera industrial apontada por Marshall é um ambiente social e econômico específico no qual a proximidade entre as empresas aumenta a velocidade dos fluxos de informaç̧ão e propicia a difusão de inovações (PORTER, 2000). Confirmando essas premissas, evidências empíricas apontam que existe uma forte relação entre proximidade espacial, spillovers de conhecimento e inovação das empresas, o que permite identificar a existência de importantes relações entre geografia e inovação (AUDRETSCH; FELDMAN, 1996).

A interação e o aprendizado resultam do processo de divisão do trabalho em que cada empresa é responsável por uma atividade ou etapa do processo produtivo. Assim, a chamada divisão cognitiva do trabalho (LOMBARDI, 2003) é capaz de estabelecer um denso canal de relacionamentos ao longo da cadeia produtiva, que possibilita a difusão do conhecimento e dos processos de aprendizado entre as firmas. lsso ocorre porque as relações do tipo usuário-produtor (de caráter vertical) propiciam o compartilhamento de experiências e de benefícios obtidos através da incorporação de melhorias e novas tecnologias no ambiente interno das empresas (BELUSSI, 2005).

É importante destacar que, além da difusão de novos conhecimentos através da interação vertical, há também um processo horizontal de transferência e absorção de conhecimento, pois a proximidade geográfica facilita a observação das empresas concorrentes e favorece a imitação ou adaptação de soluções e novas técnicas adotadas. 0 aprendizado horizontal ocorre porque as empresas podem monitorar, comparar e imitar as soluções desenvolvidas pelos seus concorrentes próximos. Dessa forma, a configuração de sistemas locais de produção propicia a criação e a manutenção de mecanismos de aprendizado local, que se desenvolvem nas dimensões horizontal e vertical (MASKELL, 2001).

Além disso, a mobilidade dos trabalhadores especializados entre as firmas também aparece como um importante mecanismo de transferência de conhecimentos técnicos e de mercado. Em virtude do aproveitamento das sinergias coletivas geradas no ambiente dos sistemas locais, os benefícios da inovação podem ser expandidos para o conjunto dos produtores, sendo difíceis de serem apreendidos por agentes externos (BELUSSI, 2005). As mudanças tecnológicas são mais fáceis de serem absorvidas e, principalmente, difundidas nos ambientes internos dos sistemas locais. Isso ocorre porque o conhecimento tecnológico encontra-se disperso entre um grande número de diferentes empresas e instituições do sistema e, ao mesmo tempo, os novos conhecimentos e informações geradas por cada uma dessas partes vão se difundindo por meio de mecanismos informais de comunicação em que se verificam baixos custos de transação (ANTONELLl, 2000).

A partir do exposto, percebe-se que a literatura sobre sistemas locais de produção aponta que um elemento-chave para a competitividade e o desenvolvimento tecnológico das firmas reside nas relações entre as empresas e, portanto, no âmbito sistêmico. Essa percepção torna-se ainda mais evidente quando se analisa os elementos que formam o embasamento teórico desses estudos, como, por exemplo, o capital social, a confiança mútua, a divisão e a especialização do trabalho entre firmas e o próprio conceito de cooperação, que possuem características interorganizacionais.

Em complemento a essa análise sistêmica, torna-se necessária a incorporação de abordagens sobre o desenvolvimento de capacitações no âmbito interno da firma, destacando como esse processo pode ser impulsionado pela aglomeração de empresas de modo a aproveitar os benefícios a ela associados. 


\section{Procedimentos metodológicos}

Como apontado anteriormente, o objetivo principal deste trabalho é analisar a contribuição da aglomeração dos produtores para o aprimoramento produtivo das pequenas empresas locais, por meio da avaliação do processo de difusão de novos conhecimentos no ambiente do sistema local de produção e da identificação de práticas semelhantes de gestão da produção entre as empresas aglomeradas. Para tanto, foram visitadas, entre setembro e outubro de 2008, 42 empresas do sistema local de produção de calçados de Franca, sendo 20 microempresas e 22 empresas de pequeno porte. Essas empresas foram escolhidas aleatoriamente de acordo com uma lista de empresas fornecida por instituições locais. As visitas e entrevistas foram se sucedendo até alcançar o total de 42 empresas, quantidade considerada suficiente para o alcance dos objetivos propostos.

Nas empresas visitadas, foram feitas entrevistas diretamente com os proprietários, que foram questionados sobre dois tópicos principais. 0 primeiro estava relacionado à adoção de novas técnicas e práticas de gestão da produção nos últimos anos, com o intuito de conhecer os processos existentes nas empresas e as ferramentas utilizadas. Nesse sentido, foi perguntado aos empresários se eles tinham desenvolvido ou adotado alguma nova prática, ou alguma nova ferramenta, de gestão da produção nos últimos três anos. 0 segundo tópico do questionário envolvia questões sobre as interações com outras empresas e fornecedores do sistema local e também sobre atividades e projetos de cooperação. Assim, foi perguntado aos empresários quais foram as fontes para o desenvolvimento e a implantação dessa nova prática ou técnica de gestão da produção, o que permitiu identificar as principais fontes de conhecimento e de informação para o aprimoramento produtivo.

Os dados coletados em cada empresa foram organizados e comparados com vistas a identificar quais eram as práticas mais difundidas no sistema local. As práticas semelhantes identificadas foram investigadas com maior profundidade para caracterizar seu processo de difusão entre as empresas do sistema local. Em um segundo momento, os transbordamentos e os mecanismos de difusão das práticas foram analisados com o propósito de identificar as principais fontes de modernização das empresas locais.

Com base em Schmitz (1997), os mecanismos de difusão foram classificados em dois tipos principais: (i) voluntários/deliberados - quando as empresas tiveram um papel ativo nos processos de difusão, por meio de atividades de cooperação, participação em projetos e contatos com outras empresas e instituições; ou (ii) involuntários/incidentais - quando o processo de difusão ocorreu sem a participação ativa das empresas, ou seja, quando a difusão ocorreu sem que houvesse nenhum esforço da empresa para tal.

Dessa forma, foi possivel compreender de forma mais apurada quais foram os mecanismos pelos quais essas empresas adquiriram novas capacitações e em que medida elas estavam relacionadas à sua presença no sistema local de produção. Tal procedimento de análise permitiu compreender os mecanismos e processos de transferência de conhecimentos adquiridos no ambiente do sistema local de produção.

\section{Análise dos mecanismos de difusão no sistema local de Franca}

As entrevistas realizadas nas empresas indicaram que, de modo geral, elas possuíam estruturas produtivas bastante semelhantes, assim como formas parecidas de gestão da produção. Dessa forma, observou-se que havia muitas práticas de gestão da produção em comum, principalmente em relação àquelas implementadas nos últimos dois anos. Essas práticas coincidentes, cuja adoção foi mais frequente entre as empresas do sistema local, foram agrupadas em três áreas principais:

- Práticas de planejamento e controle da produção;

- Práticas de administração financeira e de custos;

- Práticas de melhorias de layout e de fluxo produtivo.

Como apontado anteriormente, a análise dos dados para cada um desses grupos de práticas foi realizada com base em dois itens principais: (1) descrição das práticas coincidentes nas empresas entrevistadas; (2) identificação dos mecanismos que possibilitaram a difusão dessas práticas.

\subsection{Práticas de planejamento e controle da produção}

Nessa área, houve grande incidência de práticas semelhantes entre as empresas analisadas. As práticas coincidentes envolveram desde tarefas mais simples, como a implementação de um sistema manual para controle de entradas e saídas do estoque de matéria-prima e a utilização de fichas manuais para acompanhamento das etapas de produção, até práticas mais complexas, como a instalação de um software de Planejamento e Controle da Produção ou a integração do sistema existente com outras áreas da gestão e a utilização do sistema de código de barras.

De forma geral, verificou-se que a adoção de práticas relacionadas à área de Planejamento $\mathrm{e}$ Controle da Produção seguia uma sequência padrão, o que refletia uma evolução gradual das ferramentas 
utilizadas. Nas empresas que não possuíam software de Planejamento e Controle da Produção, o primeiro passo foi a formalização dos registros através da utilização de planilhas manuais ou computadorizadas.

Já nas empresas que já possuíam sistemas mistos, o segundo passo foi a compra de um software simples de Planejamento e Controle da Produção para armazenagem e controle das informações referentes às atividades de produção. Com o tempo, os dados foram sendo coletados com maior frequência e as empresas passaram a procurar sistemas mais completos ou buscaram a integração do sistema existente com outras áreas da empresa, como planejamento, vendas e financeiro.

Nas empresas que já possuíam sistemas integrados de Planejamento e Controle da Produção, o passo seguinte foi aumentar a informatização com o objetivo de agilizar a coleta de dados sobre a produção e garantir maior confiabilidade dos dados gerados pelo sistema. Para tanto, as empresas instalaram computadores no chão de fábrica e sistemas de leitura das fichas de produção por código de barras.

Nesse grupo de práticas, foram identificados dois mecanismos principais de difusão, com base na classificação proposta por Maskell (2001): (1) difusão "horizontal", através do contato informal com empresários e dirigentes de outras empresas locais produtoras de calçados e (2) difusão "vertical", através dos fornecedores locais especializados na venda e manutenção de softwares de Planejamento e Controle da Produção.

Os dados revelaram que esses dois mecanismos de difusão estavam relacionados aos diferentes estágios de implementação das práticas. Nas empresas que adotaram as práticas mais simples, referentes aos estágios iniciais do processo de aprimoramento da área de Planejamento e Controle da Produção, a principal motivação para a implantação foi a observação de outras empresas vizinhas ou a indicação de amigos proprietários ou funcionários de outras empresas, indicando a predominância da difusão horizontal. Já nas empresas que possuíam relações estáveis com outras empresas produtoras de calçados, a transferência ocorreu de maneira mais direta, revelando a presença de mecanismos voluntários de difusão. Em uma das empresas entrevistadas, por exemplo, a nova planilha computadorizada para controle de estoque foi adaptada a partir de uma versão disponibilizada por uma empresa vizinha.

Por outro lado, nos casos em que não havia relações abertas com outras empresas, a transferência ocorreu de maneira mais sutil, como, por exemplo, através de conversas informais dos dirigentes com funcionários ou gerentes de outras empresas, indicando a predominância dos mecanismos involuntários de difusão. Nas empresas que adotaram práticas mais avançadas na área de Planejamento e Controle da Produção, o principal mecanismo de difusão foi gerado pelo contato comercial com os fornecedores de softwares especializados em Planejamento e Controle da Produção. Quando questionados sobre a motivação para a melhoria do sistema existente, os empresários entrevistados afirmaram que se tratava de uma "evolução natural", decorrente da própria utilização do software.

Entretanto, as entrevistas demonstraram que todas as melhorias foram implementadas com o auxílio do fornecedor de software, que também era responsável por sua manutenção. Essa constatação indicou que o mecanismo predominante de difusão dessas práticas foi a difusão vertical por meio de mecanismos voluntários. Essa tendência se explica porque a implementação das práticas mais avançadas de Planejamento e Controle da Produção exigia um conhecimento técnico bastante específico, o que pode ser interpretado como uma barreira à difusão horizontal. Soma-se a isso o fato de que a implementação dessas práticas representava um objetivo comercial para as empresas fornecedoras de softwares, o que fez aumentar os esforços para estimular sua adoção nas empresas clientes.

\subsection{Práticas de administração financeira e controle de custos}

$\mathrm{Na}$ área de administração financeira e controle de custos, a principal prática identificada diz respeito à formação do custo do produto, atividade que foi considerada de grande importância para a competitividade das microempresas entrevistadas.

Nos últimos dois anos, as empresas adotaram melhorias nessa área através de quatro ações principais: (1) conhecimento de todos os fatores que devem ser calculados na planilha; (2) modificação do método utilizado; (3) utilização de planilha manual ou eletrônica; e (4) atualização dos índices da planilha. Em todos esses casos, a difusão se deu por meio de mecanismos horizontais e voluntários, representados pelos contatos com proprietários de outras empresas. Verificou-se que a formação dos custos era um tema que preocupava os microempresários, que debatiam frequentemente sobre esse assunto.

Os empresários apontaram a prática de pesquisar junto a outros produtores de calçados a planilha mais adequada aos seus procedimentos internos. No entanto, algumas empresas demonstraram não ter conseguido utilizar a planilha concedida por outro fabricante, por não compreender todos os elementos que a compunham e que foram utilizados 
na sua elaboração. Esse caso ilustra a importância da capacidade de absorção da empresa para receber os conhecimentos disponibilizados pelos mecanismos de difusão existentes. Além disso, como essas práticas estão enraizadas nas rotinas de cada uma das empresas, elas são repletas de conhecimentos de caráter puramente tácito e específico, o que dificulta a sua transferência a outras estruturas produtivas, mesmo que bastante semelhantes.

\subsection{Práticas de melhoria de layout e fluxo produtivo}

As práticas implementadas na área de layout e de fluxo produtivo representam os esforços de melhoria incremental e contínua por parte das empresas. Como consequência, não foi possível identificar um único padrão de adoção dessas práticas, já que houve grande variação de ações e soluções utilizadas pelas empresas visitadas. No entanto, a pesquisa apontou que as práticas introduzidas nessa área exerceram um papel fundamental no processo de aprimoramento produtivo das pequenas empresas, uma vez que as mudanças empreendidas geraram aumento de produtividade sem, contudo, exigir grandes investimentos.

De maneira geral, essas práticas estavam relacionadas a quatro ações principais: (1) mudanças de layout; (2) modificação da sequência de produção; (3) introdução ou eliminação de etapas do processo de fabricação; e (4) aprimoramento do modo de execução das tarefas.

As mudanças de layout eram realizadas com base na adaptação de máquinas e equipamentos ou na simples mudança do posicionamento das etapas de produção. Tais práticas eram ainda mais importantes para as empresas que fabricavam grandes variedades de produtos, pois exigia novas configurações do arranjo físico ou até mesmo a compra de novas máquinas, o que implicava em seguidas mudanças de layout e a reconfiguração de partes do fluxo produtivo.

As ações de modificação das etapas do processo produtivo envolviam a reavaliação do fluxo de produção. As práticas desse tipo geralmente estavam relacionadas à etapa de montagem, cuja sequência de tarefas era modificada para evitar desperdício de tempo e de materiais. Esse mesmo fato foi verificado nas práticas direcionadas à melhoria do modo de executar as tarefas de produção. As entrevistas indicaram que grande parte das melhorias de produtividade resultou da descoberta de maneiras mais simples de realizar as mesmas tarefas, muitas vezes com ganhos não despreziveis de produtividade.

Em todos esses casos, os processos de difusão mais significativos ocorreram por meio de interações horizontais, que foram propiciadas por uma combinação de mecanismos voluntários e involuntários. Em algumas empresas visitadas, grande parte das práticas citadas foi introduzida por funcionários que vieram de outras empresas locais, normalmente de maior porte, o que permite caracterizar um mecanismo de difusão de novos conhecimentos predominantemente incidental, já que a transferência não dependeu de ações deliberadas de interação entre essas empresas. Esses funcionários trouxeram conhecimentos importantes que passaram a ser aplicados nas pequenas empresas. Esse fenômeno é convergente com a literatura que aponta que a mobilidade dos trabalhadores é uma das formas pelas quais se manifestam os transbordamentos locais de conhecimento.

Além dos funcionários, essas práticas também foram difundidas por meio do contato entre os proprietários das empresas, que recorriam aos colegas para obter auxílio na resolução de problemas no processo produtivo. Nessas situações, eram realizadas visitas frequentes ao chão de fábrica de outras empresas, o que, consequentemente, estava restrito às empresas mais abertas do sistema local que possuíam relações frequentes com outros produtores, caracterizando, portanto, um processo de difusão a partir de ações voluntárias.

\section{Principais fontes de modernização das empresas do sistema local}

A partir da análise dos mecanismos de difusão das práticas nas três áreas apresentadas anteriormente, foi possível identificar as principais fontes de melhorias que propiciaram a adoção de novas práticas de gestão da produção nas empresas e, consequentemente, contribuíram para o seu aprimoramento produtivo. De forma geral, a pesquisa identificou duas fontes principais de modernização existentes no sistema local de produção de Franca, que foram: (1) aprendizado técnico; e (2) interação com fornecedores especializados.

A primeira fonte de melhorias identificada diz respeito ao aprendizado técnico, proporcionado pelas interações voluntárias entre empresas que buscavam solucionar problemas técnico-produtivos. Essas interações ocorriam: (1) entre proprietários; (2) entre proprietários e funcionários de outras empresas; ou (3) entre funcionários de empresas diferentes.

0 aprendizado técnico foi identificado como uma importante fonte de melhorias relacionadas a práticas de layout e fluxo produtivo. Na pesquisa, verificou-se que a base comum de conhecimento técnico existente nas empresas locais possibilitou a troca de ideias e de busca conjunta de soluções que, por sua vez, geraram novos conhecimentos que resultaram na adoção de novas práticas. As empresas 
visitadas foram questionadas sobre sua interação com outras empresas locais concorrentes, com vistas à troca de ideias e informações e resolução de problemas. Para as respostas afirmativas, foi solicitado que os entrevistados indicassem quais eram as outras empresas com as quais mantinham contato frequente. Esses dados permitiram a construção da rede de interações formada pelas empresas pesquisadas.

Os resultados estão dispostos na Figura 1, na qual a grande quantidade de vértices isolados representa as empresas que não possuíam nenhum tipo de interação voluntária com outras empresas, com o objetivo específico de trocar ideias e resolver problemas. Esses dados estão em consonância com os resultados verificados em outros trabalhos, que demonstraram a pequena ocorrência de relações interativas e de cooperação no sistema local de Franca, onde um clima de desconfiança, criado a partir de diversas experiências malsucedidas de interação, inibe o desenvolvimento de ações cooperativas mais intensas (SUZIGAN et al., 2001; GARCIA; MOTTA; AMATO NETO, 2004).

De modo geral, a Figura 1 apresenta um padrão de interação bastante concentrado, que aponta para a existência de pequenos grupos de empresas que interagem entre si. Como consequência, as interações voluntárias entre as empresas entrevistadas ocorriam de maneira bastante seletiva e eram restritas a pequenos agrupamentos.

Além disso, a Figura 1 também permite identificar dois grupos principais de empresas que interagiam frequentemente entre si. 0 primeiro, localizado na extremidade direita da figura, corresponde a um conjunto formado predominantemente por microempresas, que eram bastante dinâmicas e participativas no âmbito do sistema local. Um ponto em comum nessas empresas é que todas elas faziam parte de uma iniciativa coletiva coordenada pelo escritório de Franca do SEBRAE ou já haviam participado de algum programa de apoio oferecido pelas instituições locais.

Constatou-se, assim, que essas empresas que se mostraram mais ativas e abertas e que estavam

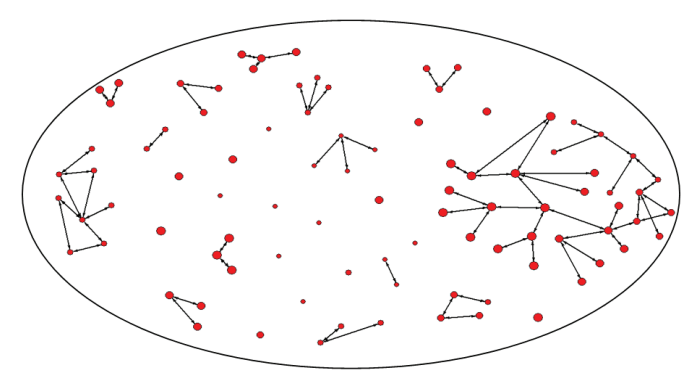

Figura 1. Representação gráfica da rede de interação entre empresas do sistema local. Fonte: Elaborado com base nos dados da pesquisa de campo. envolvidas em uma trajetória de crescimento, tendiam a se aproximar dos programas locais de capacitação com maior facilidade, o que potencializava os seus processos internos de aprendizagem. Ao mesmo tempo, observou-se que, por conta da existência de efeito de retroalimentação, o contato frequente com as outras empresas tinha o resultado de reforçar os novos conhecimentos adquiridos por meio do aprendizado técnico que, por sua vez, viabilizava a absorção de novas capacitações.

0 segundo grupo de empresas interativas, que pode ser visualizado na extremidade esquerda da Figura 1, era formado predominantemente por empresas de pequeno porte que tinham em comum o fato de estarem engajadas em projetos internos de melhoria da produção e desenvolvimento de novos produtos. As empresas frequentemente trocavam informações nessas áreas por meio de visitas e conversas informais. Entretanto, as entrevistas demonstraram que, nesse segundo grupo, as interações foram mais valorizadas pelas menores empresas, para as quais o contato com as empresas maiores e mais avançadas foi de grande importância para a implementação de novas práticas e técnicas de gestão da produção nos últimos anos. Nos dois casos, observou-se que os laços de amizade, os fatores socioculturais, a proximidade geográfica e, algumas vezes, o grau de parentesco entre os proprietários foram os fatores determinantes para a formação dos grupos de interação. Além da solução de problemas técnico-produtivos, as empresas dos grupos também trocavam ideias sobre as tendências de mercado.

Por outro lado, é importante observar que, apesar do aprendizado técnico estar restrito a pequenos grupos de empresas, a pesquisa identificou a presença de práticas muito semelhantes tanto nas empresas isoladas como nas empresas pertencentes a grupos diferentes. Essa aparente contradição pode ser explicada pela existência de mecanismos de difusão horizontal que independiam da ação das empresas e, portanto, eram involuntários. Como já apontado anteriormente, esses mecanismos involuntários se manifestavam principalmente de duas formas: (1) mobilidade dos funcionários; e (2) a observação e imitação das empresas concorrentes, sem que necessariamente houvesse contato direto entre elas.

Esses mecanismos de difusão involuntária permitiram que as práticas resultantes do processo de aprendizado técnico, advindo da interação entre as empresas aglomeradas, fossem difundidas de forma mais homogênea, atingindo as demais empresas locais. Nesses casos, é importante destacar que esse tipo de difusão foi viabilizado pela proximidade das práticas em relação à base de conhecimento existente no sistema local. Esse resultado é convergente com a existência de um sistema de conhecimento local, 
que foi apontado por Maskell (2001). Esse sistema de conhecimento, que constitui uma das bases da competitividade de empresas aglomeradas, se sobrepõe ao que o autor chamou de sistema de produção.

Outra importante fonte de melhoria verificada foram os fornecedores, que contribuíram para a implementação de práticas avançadas de gestão da produção, especialmente na área de controle da qualidade. Foram identificadas duas práticas principais introduzidas nas empresas como resultado de sua interação com os fornecedores: (1) controle de defeitos no processo; e (2) utilização da cola à base de água. Nesses casos, verificou-se que as práticas de prestação de serviços dos fornecedores, associadas à venda dos produtos, foram um elemento importante para impulsionar a adoção dessas novas práticas. No entanto, a complexidade dos conhecimentos envolvidos exigiu comprometimento e participação ativa das empresas para que a implementação das práticas introduzidas pelos fornecedores fosse bem-sucedida. Isso foi necessário porque essas práticas envolviam conhecimentos inéditos para as empresas que não estavam diretamente relacionadas à base de conhecimento existente no sistema local. Esse é o caso especificamente do uso de cola à base de água, uma vez que a superioridade técnica desse tipo de adesivo, em comparação com a cola à base de solvente, tornou imperativa a adoção dessa nova tecnologia. No entanto, para isso, as empresas precisaram efetuar mudanças em seus processos de produção, atividade na qual a participação dos fornecedores foi fundamental.

A análise das interações das empresas visitadas com os seus fornecedores indicou que a interação vertical foi uma importante fonte de melhoria para as firmas locais. Nas entrevistas, as empresas foram solicitadas a indicar os principais fornecedores (incluindo todos os tipos de materiais e serviços) com os quais mantinham contato frequente para troca de ideias e busca de soluções técnicas. 0 resultado pode ser visualizado na Figura 2.

Na Figura 2, observa-se que os fornecedores interagiam com um grande número de empresas, o que teve o efeito de reforçar os mecanismos de difusão das melhorias introduzidas nas empresas clientes. $\mathrm{Na}$ maior parte dos casos, as mesmas soluções técnicas eram oferecidas para diferentes empresas. A Figura 2 também aponta que a maior parte das relações estava concentrada em um único fornecedor, representado pela empresa fornecedora de adesivos e selantes (cola) do grupo Amazonas, grupo que controla diversas empresas locais que atuam em diversos segmentos produtores de insumos para calçados e se configura como um importante fornecedor de componentes para as empresas locais.

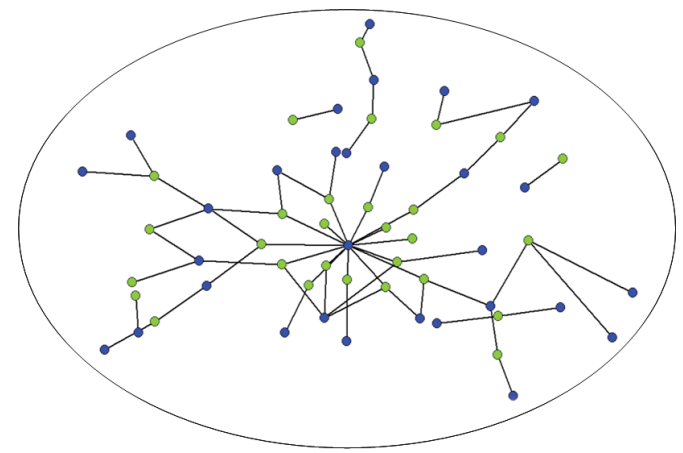

O Produtores de calçados

- Fornecedores

Figura 2. Representação gráfica da rede de interação entre empresas e fornecedores locais. Fonte: Elaborado com base nos dados da pesquisa de campo.

Esses resultados corroboram a análise do padrão de difusão das práticas de gestão no sistema local, uma vez que as práticas mais difundidas por meio dos fornecedores foram aquelas relacionadas ao processo de colagem do calçado. Dessa forma, observou-se que a empresa do grupo Amazonas atuava como uma importante fonte de melhorias para as pequenas empresas locais, o que contribuiu para a difusão de novas práticas de gestão da produção. Sobre esse ponto, verificou-se que, para a empresa do grupo Amazonas, a prestação de serviços era utilizada como uma importante ferramenta no processo competitivo, uma vez que atrelava a prestação de serviços à venda dos seus produtos. De fato, as entrevistas confirmaram que essa estratégia de atuação no mercado surtiu efeitos positivos, já que a empresa mantinha relações estáveis e duradouras com a maior parte de seus usuários.

De forma geral, a análise das fontes de melhorias do sistema local e dos transbordamentos locais de conhecimento que propiciaram a difusão dessas melhorias na forma de novas práticas de gestão da produção demonstrou a existência de diferentes padrões de difusão. Essas diferenças serão discutidas na próxima seção, com o intuito de ressaltar seu papel como uma das principais contribuições da aglomeração dos produtores para o processo de aprimoramento produtivo das pequenas empresas locais.

\section{Avaliação da contribuição da aglomeração dos produtores para 0 aprimoramento produtivo das pequenas empresas locais}

A análise dos dados coletados na pesquisa de campo apontou a importante ocorrência de transbordamentos locais de conhecimentos, que 
foram identificados através da identificação de práticas semelhantes de gestão da produção entre as empresas locais. Como apontado anteriormente, esses transbordamentos se deram por meio de diferentes mecanismos de difusão e estiveram relacionados a grupos ou "famílias" de práticas.

0 estudo do processo interno de aprendizagem, que possibilitou a adoção de novas práticas pelos produtores, permitiu detectar a origem dos conhecimentos que motivaram o aprimoramento produtivo das empresas, resultando na identificação das principais fontes de melhorias do sistema local. Os dados revelaram a existência de uma forte relação entre (1) as fontes de melhorias do sistema local; (2) as práticas adotadas pelas empresas; e (3) os mecanismos de difusão predominantes. Essas correlações estão dispostas no Quadro 1 a seguir.

0 Quadro 1 mostra que a natureza dos processos de difusão no sistema local foi determinada pelas características dos conhecimentos (práticas) transferidos: quanto mais as práticas transferidas se aproximavam da base de conhecimento das empresas locais, mais simples eram os processos de difusão (utilização de mecanismos horizontais e involuntários). 0 contrário também é valido: quanto mais o conhecimento transferido se distanciava da base de conhecimento das empresas locais, mais complexos eram os mecanismos de difusão utilizados.

Como consequência, o aprendizado técnico foi responsável por melhorias relacionadas a práticas de caráter incremental. Essas práticas envolviam aspectos técnicos que se aproximavam da base de conhecimento local e, por isso, foram mais fáceis de serem difundidas. Isso explica a predominância de mecanismos involuntários de difusão nesse grupo. Por outro lado, as práticas mais avançadas introduzidas nas empresas, principalmente através dos fornecedores, tinham um elevado conteúdo técnico que não fazia parte da base comum de conhecimentos do sistema local. Consequentemente, a maior parte das empresas demonstrou ter uma capacidade de absorção limitada para esse grupo de práticas mais avançadas.

Quadro 1. Classificação das fontes de modernização do sistema local.

\begin{tabular}{ccc}
$\begin{array}{c}\text { Fonte de } \\
\text { modernização }\end{array}$ & $\begin{array}{c}\text { Caracteristicas das } \\
\text { práticas introduzidas } \\
\text { nas empresas }\end{array}$ & $\begin{array}{c}\text { Mecanismo } \\
\text { de difusão } \\
\text { predominante }\end{array}$ \\
\hline $\begin{array}{c}\text { Aprendizado } \\
\text { técnico }\end{array}$ & $\begin{array}{c}\text { Mais simples, de caráter } \\
\text { incremental } \\
\text { Mais complexas, que } \\
\text { Fornecedores }\end{array}$ & $\begin{array}{c}\text { Difusão horizontal } \\
\text { involuntária }\end{array}$ \\
& $\begin{array}{c}\text { significativas nas } \\
\text { empresas }\end{array}$ & $\begin{array}{c}\text { Difusão vertical } \\
\text { voluntária }\end{array}$ \\
\hline
\end{tabular}

Fonte: Elaboração própria com base nos dados da pesquisa de campo.
Nesses casos, os processos de difusão exigiram, necessariamente, a criação de mecanismos deliberados de difusão de novos conhecimentos entre as empresas, o que, por esse motivo, demandou um período maior de interação e de construção das relações entre os agentes. Por outro lado, essas interações se tornaram mais duradouras e foram sendo caracterizadas por conteúdos mais complexos, o que resultou em resultados mais expressivos em termos do processo de implementação das práticas nas empresas. Esse é o caso típico das interações entre os produtores e seus fornecedores de insumos, com destaque para o caso dos fornecedores de adesivos. Interessante notar que, ao contrário dos resultados da pesquisa de Silva (2007), que identificou a importância das relações usuárioprodutor para a indústria de máquinas para calçados, não foi identificado papel relevante dos fornecedores de máquinas e equipamentos. A principal razão para isso deve residir no perfil das empresas que compuseram a amostra da pesquisa que deu origem a este trabalho, composta basicamente por microempresas e empresas de pequeno porte. Essas empresas, em geral, adquirem apenas máquinas reformadas de segunda-mão e, por isso, não conseguem se beneficiar de interações mais expressivas com os fornecedores de máquinas.

Essas constatações indicam a existência de barreiras à difusão de conhecimentos complexos, relacionados às práticas mais avançadas de gestão da produção. Tal afirmação é convergente com os resultados de Giuliani e Bell (2005), que demonstraram que o processo de difusão do conhecimento em sistemas locais de produção ocorre de maneira seletiva e não homogênea, de acordo com a capacidade de absorção das empresas. Os autores apontaram que as práticas que exigiam conhecimentos mais complexos que não faziam parte da base comum de conhecimentos do sistema local eram difundidas apenas entre um grupo seleto de empresas com capacidade de absorção mais elevada.

Esses resultados ajudam a explicar as diferenças entre os padrões de difusão das principais fontes de melhorias apontadas no Quadro 1, já que a variação dos mecanismos de difusão foi determinada pela base de conhecimento existente nas empresas locais. Tais considerações reforçam o importante papel das capacitações internas da firma sobre o processo de apropriação das vantagens proporcionadas pela aglomeração das empresas.

\section{Considerações finais}

Um dos pressupostos teórico-conceituais mais importantes para a análise de sistemas locais de produção é que as empresas localizadas, especialmente as de pequeno e médio porte, são capazes de adquirir 
novas capacitações através do acesso a fontes externas locais de informação e de conhecimento. Ao partir desse pressuposto, este trabalho analisou a influência dos mecanismos de difusão de novos conhecimentos junto a pequenas empresas localizadas em sistemas locais de produção. Para isso, foi feito um levantamento de informações junto a um conjunto de pequenos produtores de calçados do sistema local de Franca, em que foram realizadas duas perguntas principais: se a empresa adotou alguma melhoria em seus processos produtivos e de gestão da produção e quais foram as fontes dessas melhorias.

Em convergência com os pressupostos conceituais, a pesquisa foi capaz de verificar que, em geral, os processos internos de aprendizagem nas empresas foram reforçados por mecanismos locais de difusão de informação e de novos conhecimentos, de modo que esses novos conhecimentos necessários para a implementação de novas práticas de gestão da produção fossem mais bem aproveitados entre as empresas locais. Entre os mecanismos verificados, foram encontrados alguns de caráter puramente incidental, relacionados com formas de interação verificadas tipicamente em sistemas locais de produção, e outros mecanismos deliberados, criados por meio do estabelecimento e da manutenção de interações expressivas e frequentes entre os agentes.

Ao mesmo tempo, verificou-se que os benefícios da aglomeração produtiva, que se manifestam por meio das economias externas locais geradas nessas estruturas industriais, podem ser mais bem aproveitados pelas empresas, quanto maior for sua capacidade de absorção desses novos conhecimentos. A presença de capacitações expressivas entre as empresas locais é capaz inclusive de estimular a manutenção de interações mais substantivas entre os agentes, com efeitos positivos para a acumulação de novos conhecimentos.

De modo geral, observou-se que os processos de difusão de conhecimento que se desenvolveram no âmbito do sistema local de produção tiveram grande importância para o aprendizado e para a transferência de novas capacitações. Nesse ambiente, as novas práticas introduzidas em algumas empresas puderam se disseminar rapidamente para o conjunto de produtores, potencializando o processo de aprimoramento do sistema local como um todo. Por outro lado, as empresas que possuíam maiores capacitações apresentaram maior capacidade de absorção, o que fez com que os benefícios da aglomeração fossem apropriados de forma desigual, demonstrando que essas vantagens podem ser mais bem aproveitadas pelas empresas com maior capacidade de absorção.

Isso tem implicações importantes para as políticas públicas voltadas a sistemas locais de produção e, especialmente, para as pequenas empresas, que são tipicamente encontradas em estruturas produtivas localizadas. Os programas de apoio voltados ao desenvolvimento competitivo de pequenas empresas em sistemas locais de produção devem envolver necessariamente mecanismos de criação e de reforço das capacitações internas dos produtores, uma vez que isso pode potencializar a apropriação pelas empresas dos benefícios gerados pela aglomeração produtiva.

\section{Agradecimentos}

Os autores agradecem o apoio financeiro da Fapesp por meio de seu programa Projeto Temático (processo número 06/58.878-8) e do CNPq, por meio do Edital Universal (processo número 401.529/2010-0). Agradecem também os comentários de Marcelo Pinho, Alceu Alves Filho e de um parecerista anônimo. As insuficiências, como de praxe, são de responsabilidade exclusiva dos autores.

\section{Referências}

ANTONELLl, C. Collective Knowledge Communication and Innovation: The Evidence of Technological Districts. Regional Studies, v. 34, n. 06, p. 535-547, 2000. http:// dx.doi.org/10.1080/00343400050085657

AUDRETSCH, D.; FELDMAN, M. P. R\&D Spillovers and the geography of innovation and production. American Economic Review, v. 86, p. 630-640, 1996.

BELUSSI, F. On the Theory of Spatial Clustering: the emergence if various forms of agglomeration. In: BELUSSI, F.; SAMMARRA, A. (Eds.). Industrial Districts, Relocation and the Global Value Chain. Grafica di copertina, Carlo Fumian, 2005.

COHEN, W.; LEVINTHAL, D. Absorptive Capacity: A new perspective on learning and innovation. Administrative Science Quarterly, v. 35, p. 128-152, 1990. http://dx.doi. org/10.2307/2393553

GARCIA, R.; MOTTA, F.; AMATO NETO, J. Uma análise das Características da Estrutura de Governança em Sistemas Locais de Produção e suas Relações com a Cadeia Global. Gestão \& Produção, v. 11, n. 3, p. 343-354, 2004. http:// dx.doi.org/10.1590/S0104-530X2004000300008

GIULIANI, E.; BELL, M. The Micro-determinants of Meso-level Learning and Innovation: evidence from a Chilean wine cluster. Research Policy, v. 34, n. 1, p. 47-68, 2005. http://dx.doi.org/10.1016/j.respol.2004.10.008

LA ROVERE, R. Perspectivas das Micro, Pequenas e Médias Empresas no Brasil. Revista de Economia Contemporânea, v. 5, ed. especial, p. 20-38, 2001.

LOMBARDI, M. The Evolution of Local Production Systems: the emergence of the "invisible mind" and the evolutionary pressures towards more visible "minds". Research Policy, v. 32, n. 9, p. 1443-1462, 2003. http:// dx.doi.org/10.1016/S0048-7333(02)00157-9

MARSHAll, A. Princípios de Economia. São Paulo: Nova Cultura, 1920.

MASKELL, P. Towards knowledge-based theory of the geographical cluster. Industrial and Corporate Change, 
v. 10, p. 921-943, 2001. http://dx.doi.org/10.1093/ icc/10.4.921

ORGANIZATION FOR ECONOMIC CO-OPERATION AND DEVELOPMENT - OECD. Small Businesses, Job Creation and Growth: facts, obstacles and best practices. OECD, 1997.

PORTER, M. Location, competition, and economic development: local clusters in a global economy. Economic Development Quarterly, v. 14, n. 1, p. 15-34, 2000. http://dx.doi.org/10.1177/089124240001400105

SCHMITZ, H. Collective efficiency and increasing returns. Brighton: University of Sussex, 1997. (IDS Working Paper, n. 50).

SILVA, A. Relações usuário-produtor e aprendizado inovativo em sistemas locais de produção: uma análise de interações na indústria de máquinas para calçados e seus usuários. 2007. Dissertação (Mestrado em Engenharia de Produção)-Universidade de São Paulo, São Paulo, 2007.

SOUZA, M. Pequenas e médias empresas na reestruturação industrial. Brasília: Ed. SEBRAE, 1995.

SUZIGAN, W. (Coord.). Identificação, Mapeamento e Caracterização Estrutural de Arranjos Produtivos Locais no Brasil. Instituto de Pesquisa Econômica Aplicada - IPEA, 2006. Relatório Consolidado.

SUZIGAN, W. et al. Sistemas produtivos locais no Estado de São Paulo: o caso da indústria de calçados de Franca. In: TIRONI, L. T. (Org.). Industrialização descentralizada: sistemas industriais localizados. Brasília: IPEA, 2001.

\section{An evaluation of the dissemination of manufacturing process improvement among small firms in local production systems} Abstract

There is a growing yield in the literature on the main determinants of the competitiveness of small and medium enterprises. One important contribution in this way is the assumption that the clustering of firms can bring them strong benefits, also in terms of productive improvement. Based on these assumptions, this paper aims to exam the main effects of the clustering firms on the manufacturing process upgrading of small firms, by the analysis of the dissemination of manufacturing practices and tools in local systems. To this end, a survey with 42 small footwear producers was carried out at the local system of Franca, Brazil. The study investigated the existence of manufacturing process improvement among these firms and the main sources of information for the dissemination of these tools. The main results show that the clustering firms can stimulate the adoption of new manufacturing management practices, through both deliberate channels of dissemination of new knowledge among firms and the spontaneous ways of information exchange, which are usual in these local production systems. In addition, it was possible to notice that the level of appropriability of these benefits depends on the existence of previous knowledge inside firms, that is, their absorption capacity.

\section{Keywords}

Small firms. Operations management. Local production systems. Industrial clusters. Productive improvement. APL. 